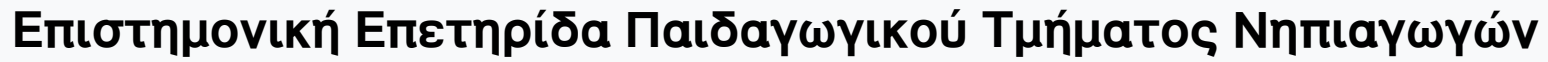

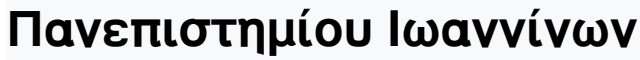

Tóp. 9, Ap. 2 (2016)

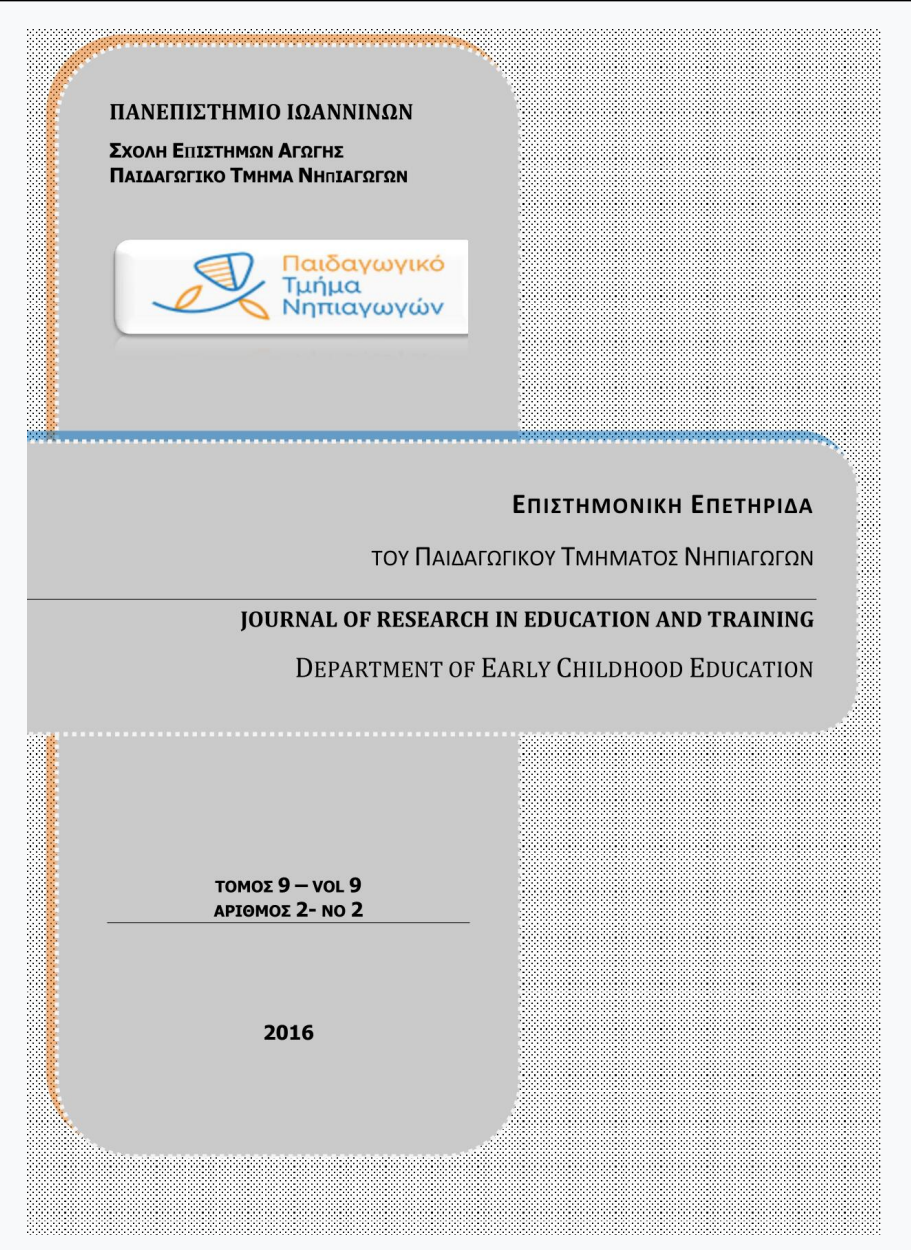

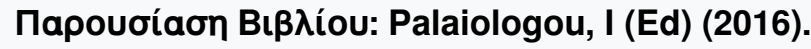
The Early Years Foundation Stage: Theory and Practice. London: Sage ISBN: 9781446256985

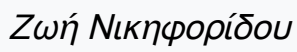

doi: $10.12681 /$ jret.10783

Copyright @ 2016, Zwń Nıкnчopídou

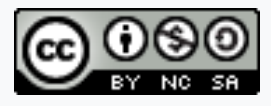

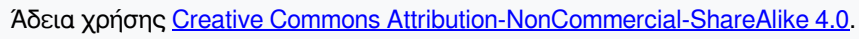

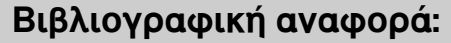

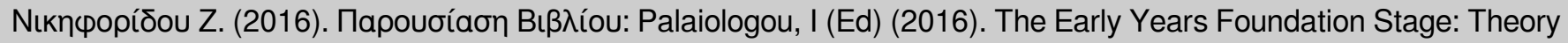

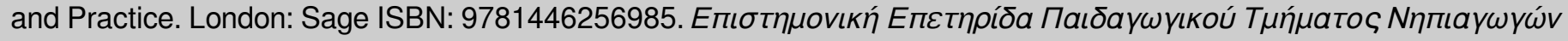

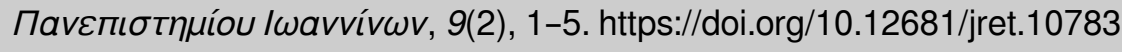




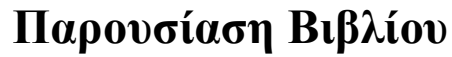

\section{Palaiologou, I (Ed) (2016). The Early Years Foundation Stage: Theory and Practice. London: Sage ISBN: 9781446256985}

\author{
Z \\ Department of Early Childhood \\ Liverpool Hope University
}

To $\beta 1 \beta \lambda$ ío «The Early Years Foundation Stage: Theory and Practice» $\pi \rho \alpha \gamma \mu \alpha \tau \varepsilon v ́ \varepsilon \tau \alpha 1$

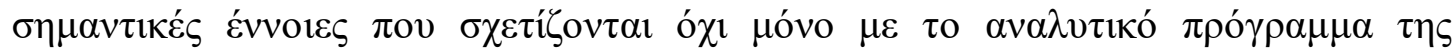

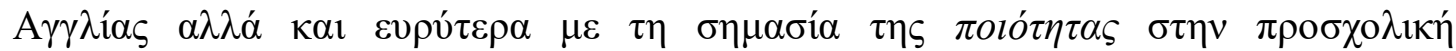

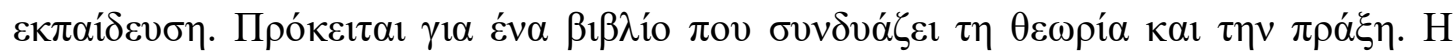

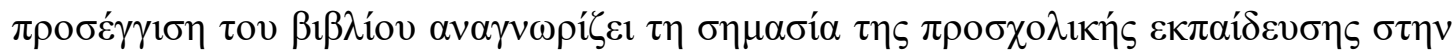

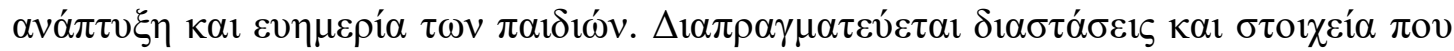

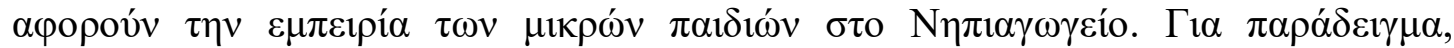

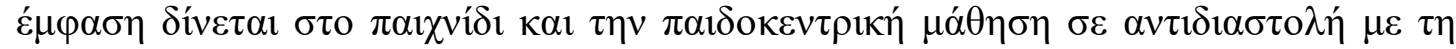

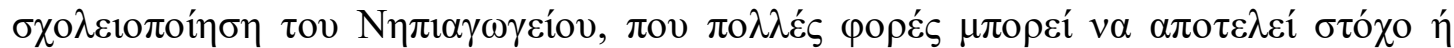

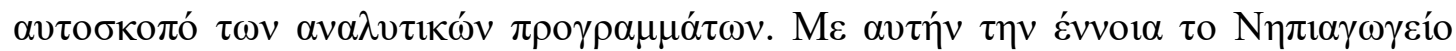

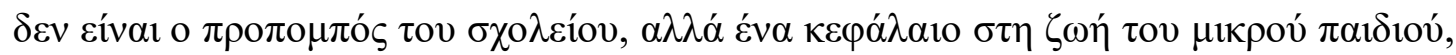

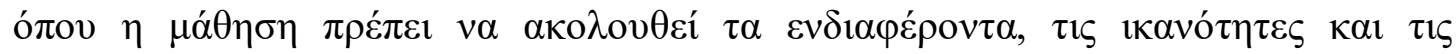

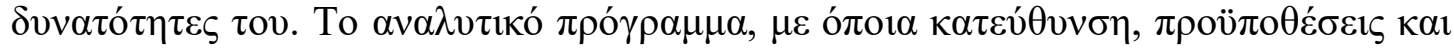

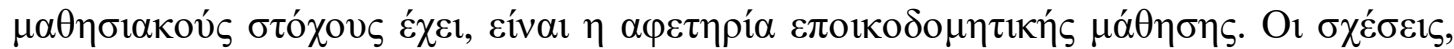

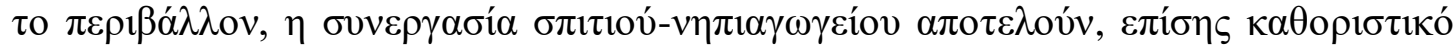

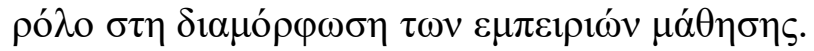

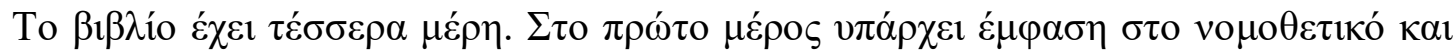

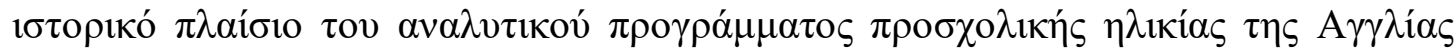

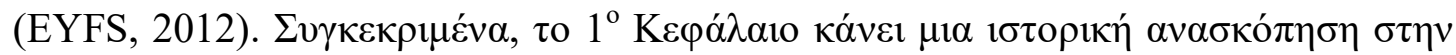

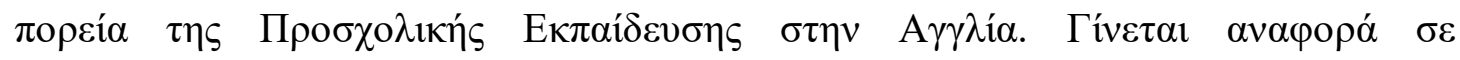

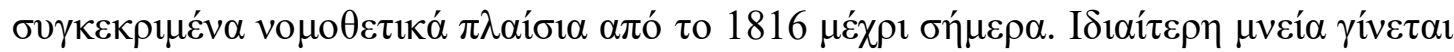

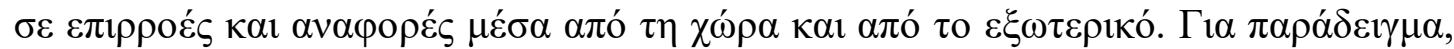

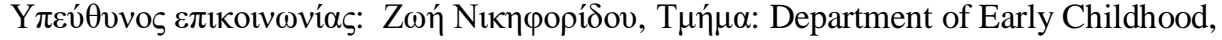

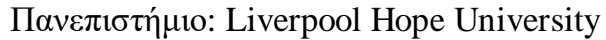
e-mail: nikifoz@hope.ac.uk

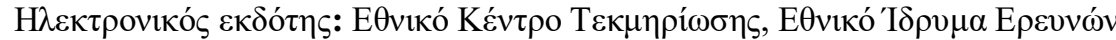
URL: http://ejournals.epublishing.ekt.gr/index.php/jret/index
} 


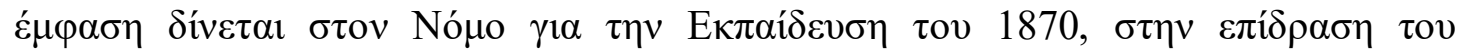

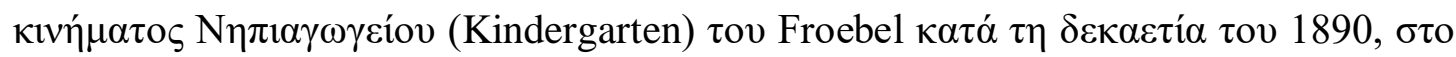

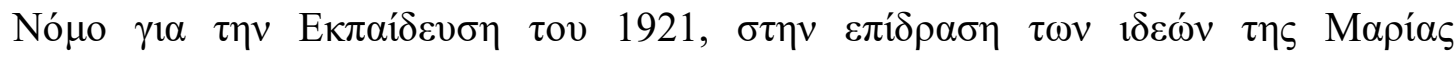

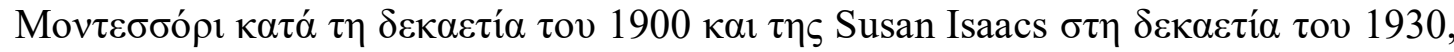

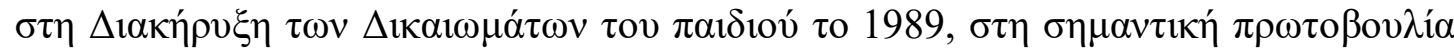

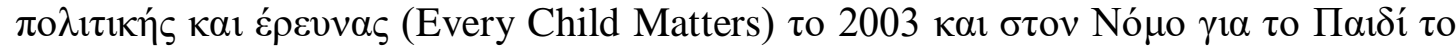
2004.

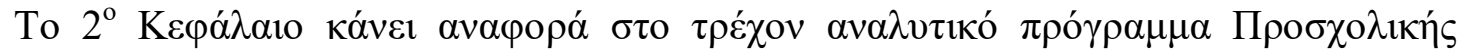

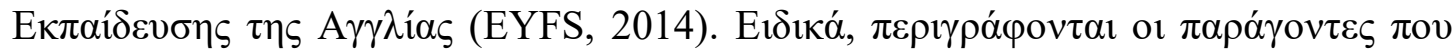

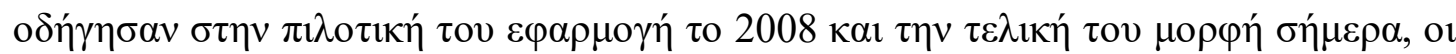

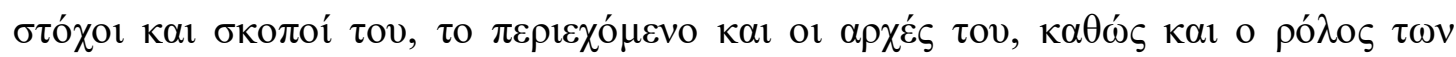

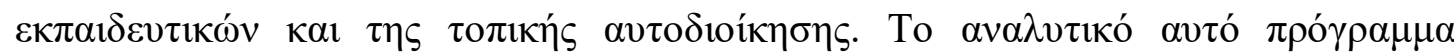

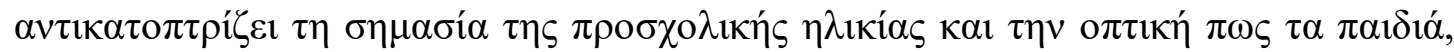

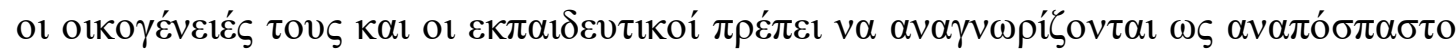

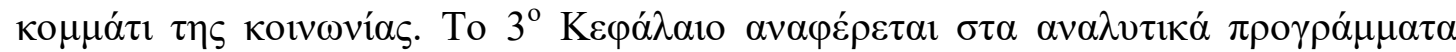

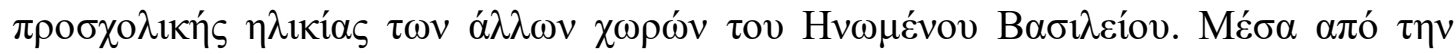

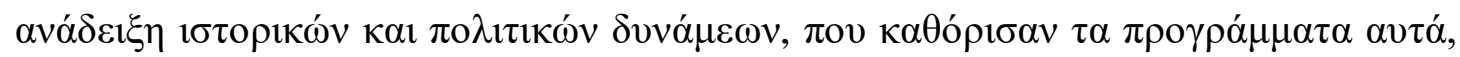

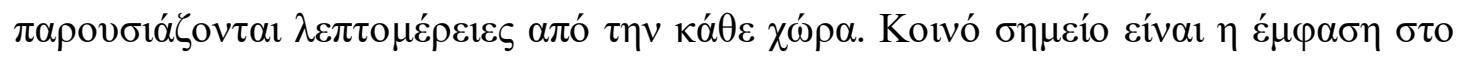

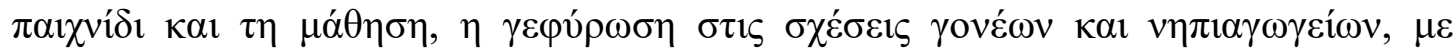

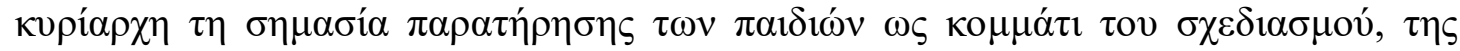

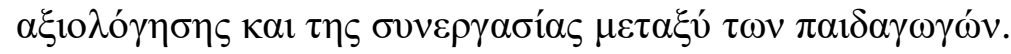

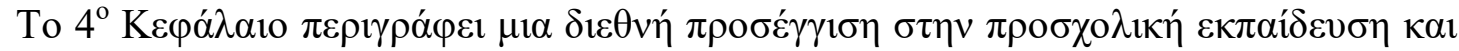

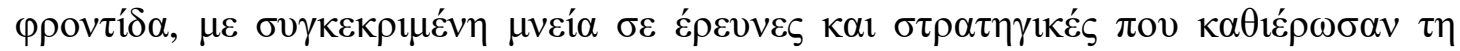

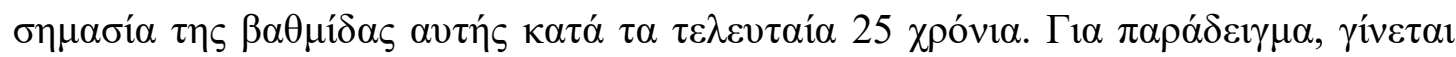

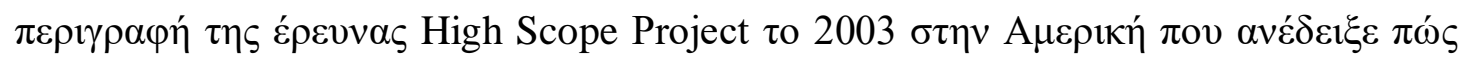

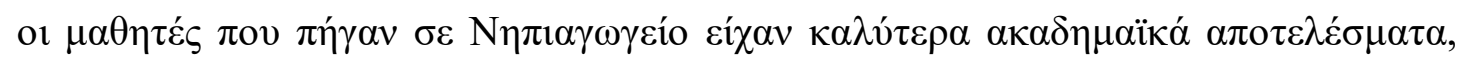


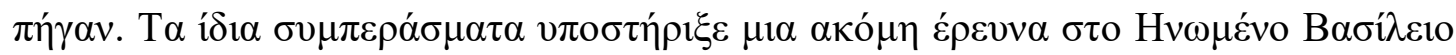

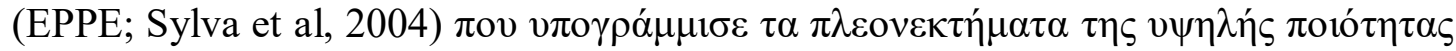

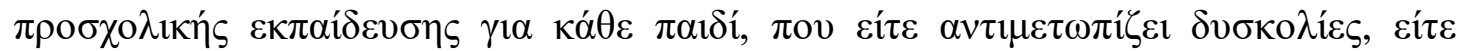

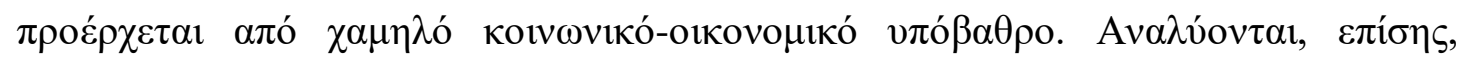

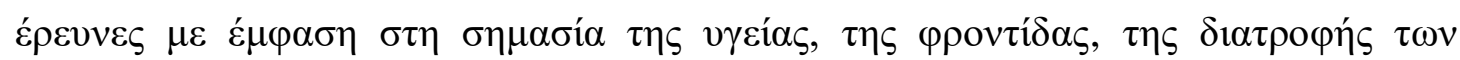




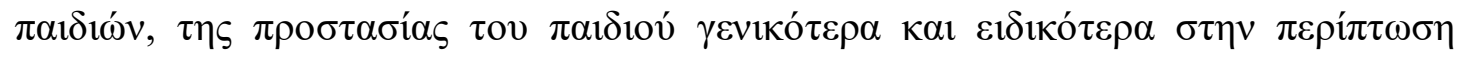

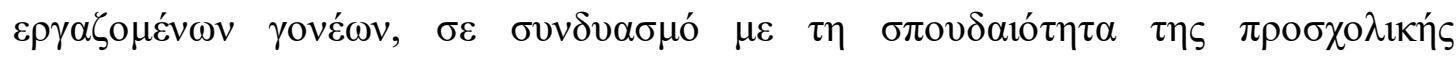

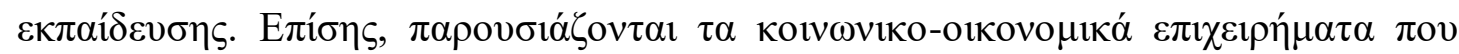

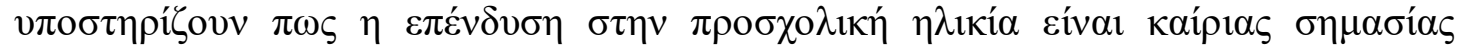

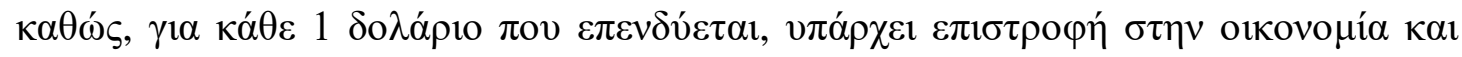

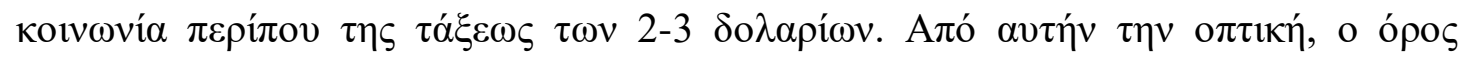

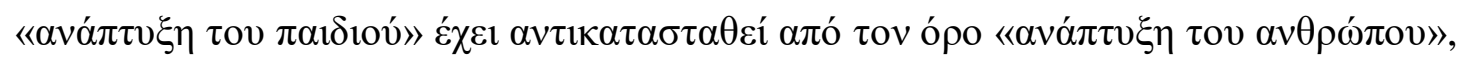

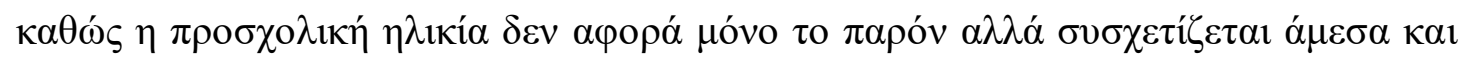

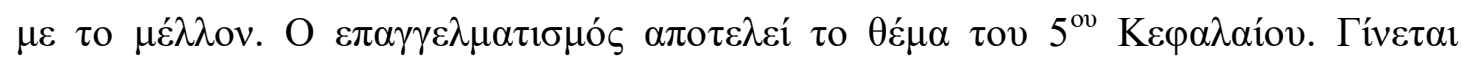

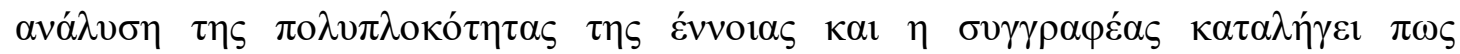

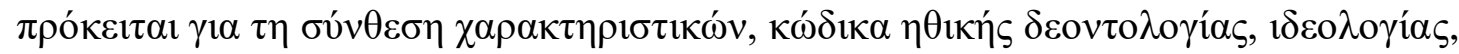

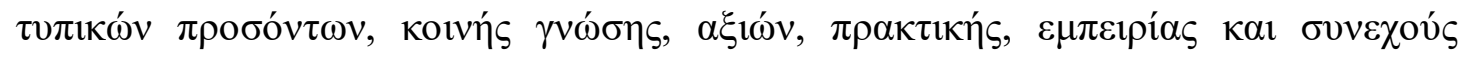
$\alpha \xi 10 \lambda o ́ \gamma \eta \sigma \eta \varsigma \kappa \alpha 1 \alpha v \alpha ́ \pi \tau v \xi \eta \varsigma$.

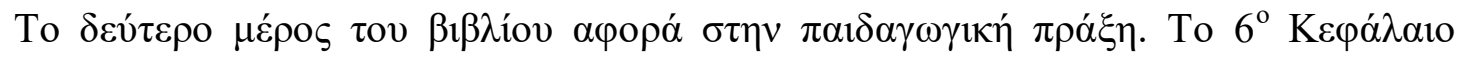

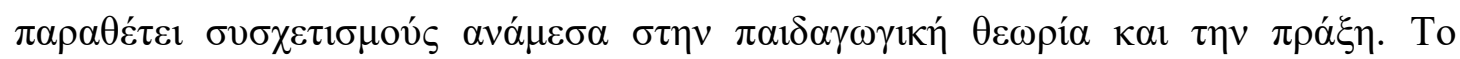

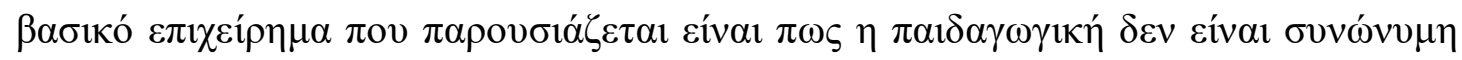

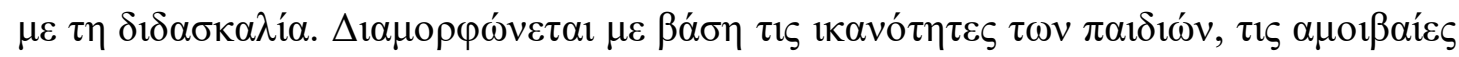

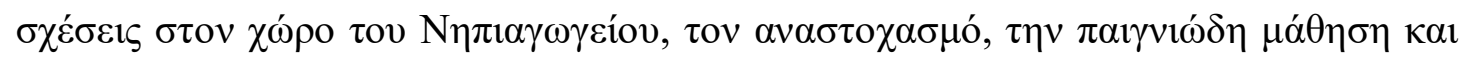

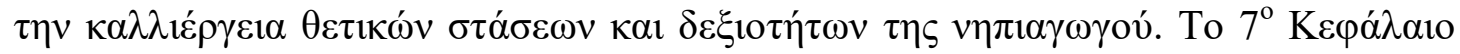

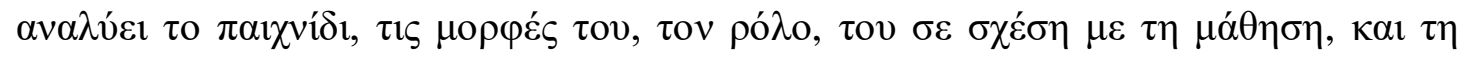

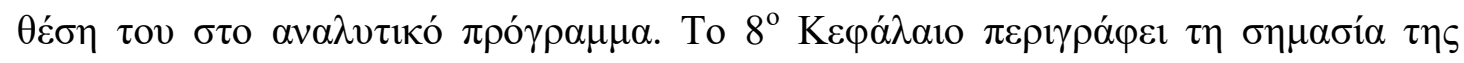

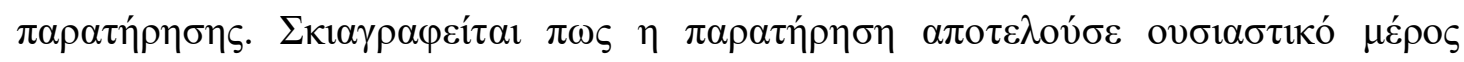

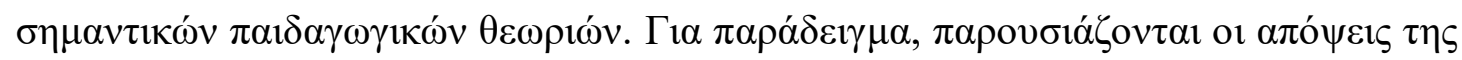

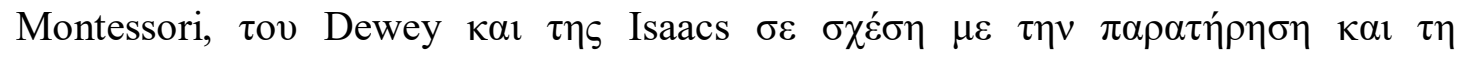

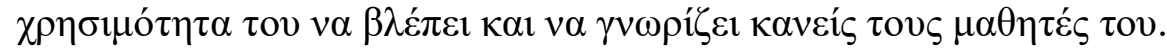

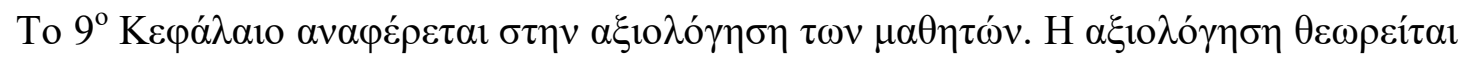

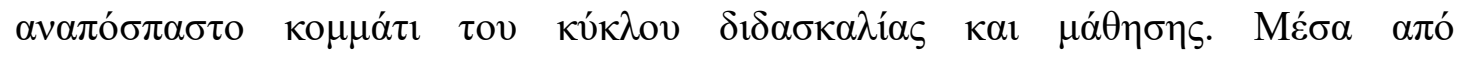

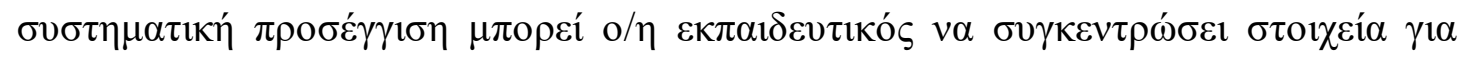

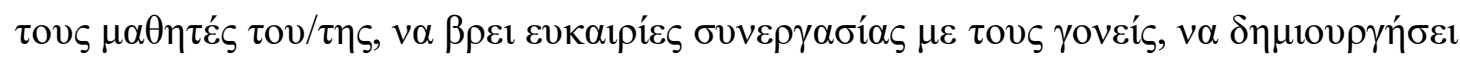

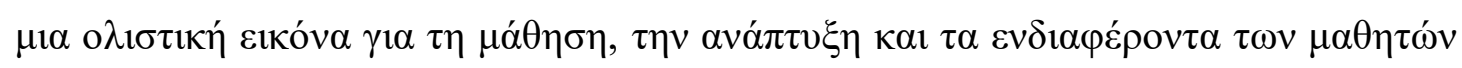

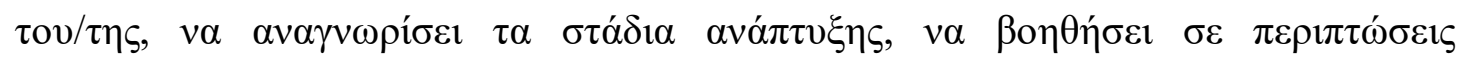

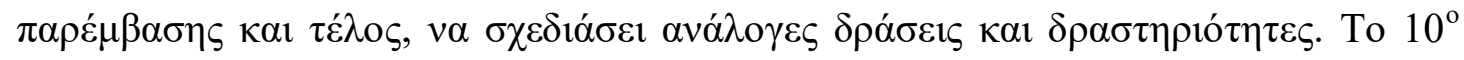




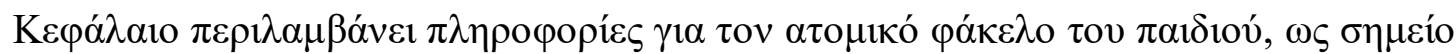

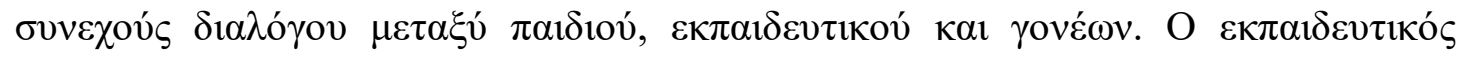

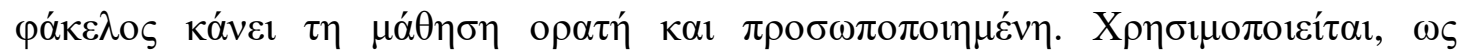

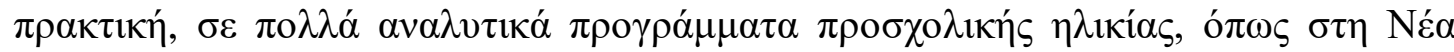

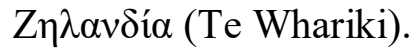

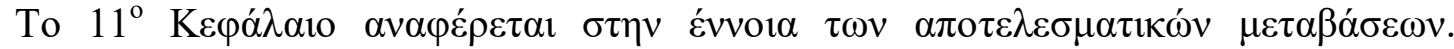

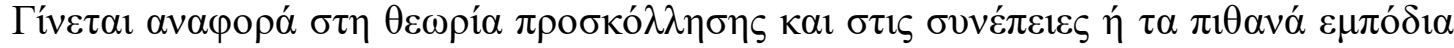

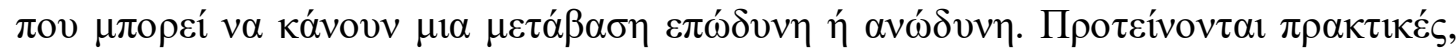

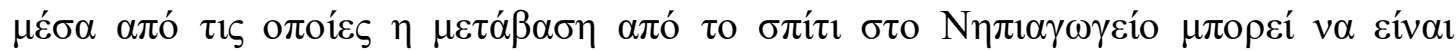

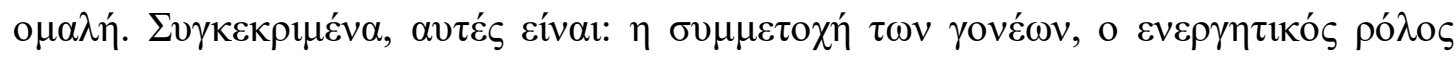

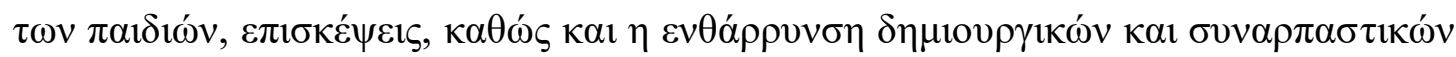

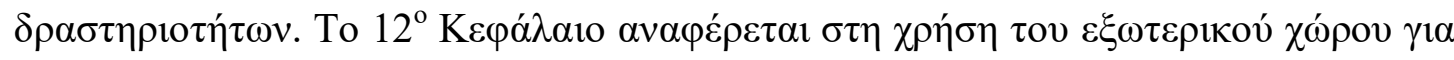

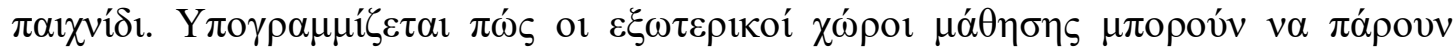

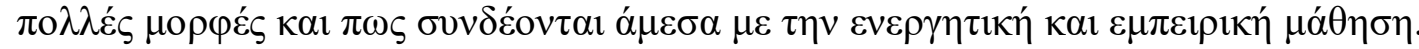

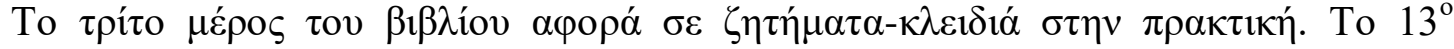

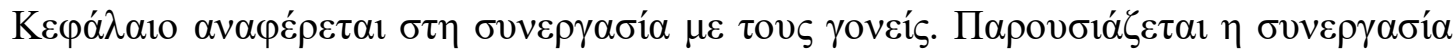

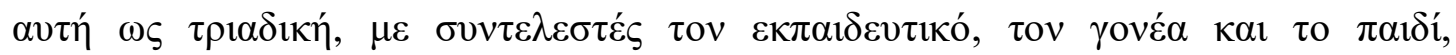

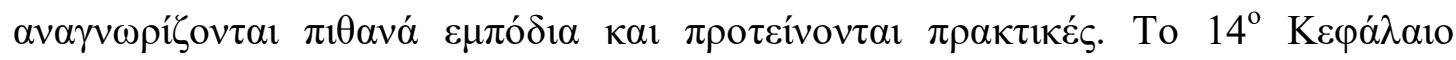

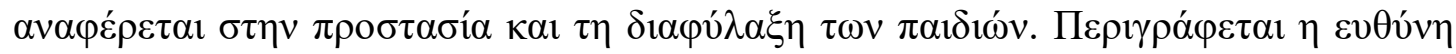

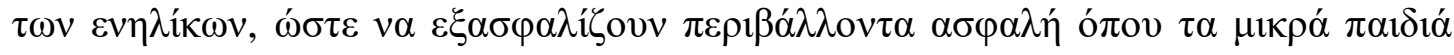

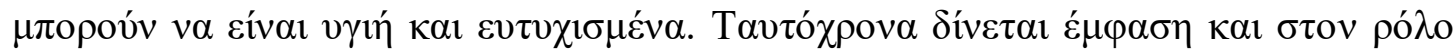

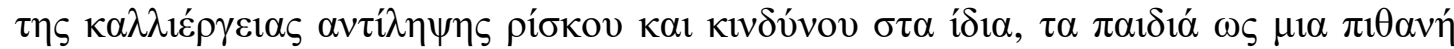

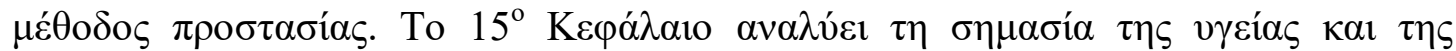

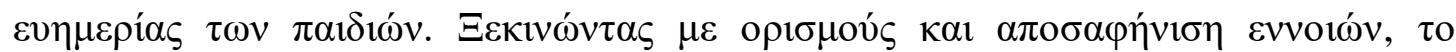

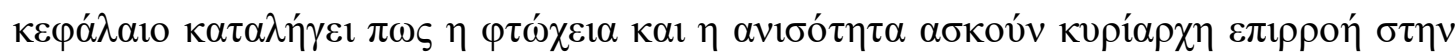

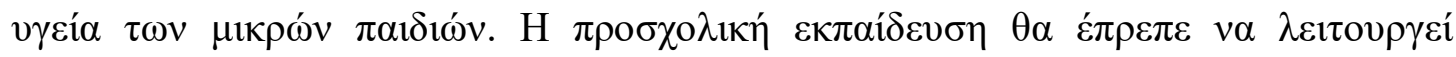

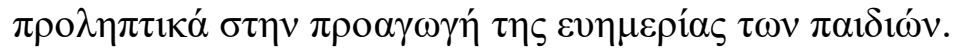

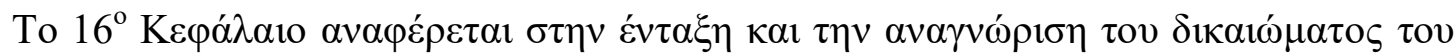

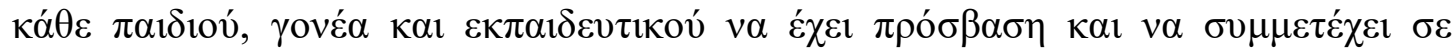

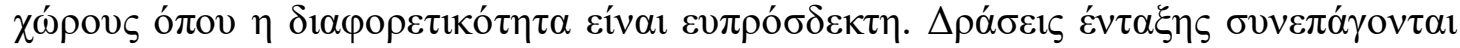

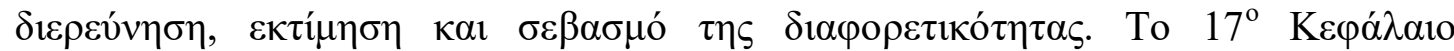

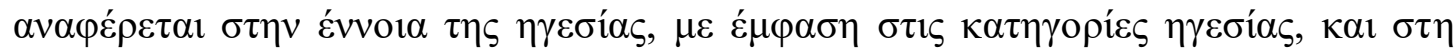




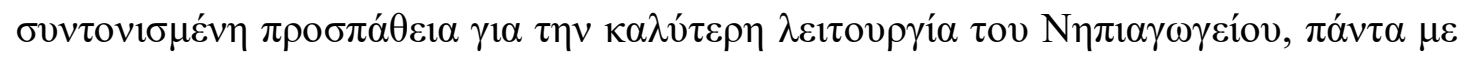

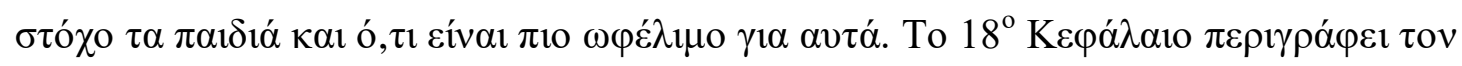

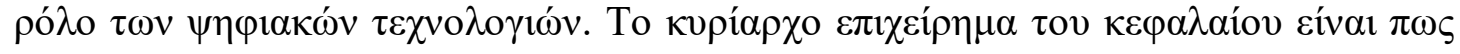

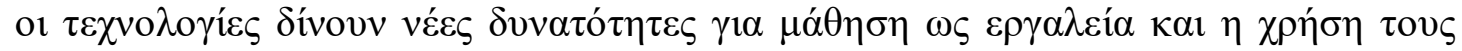

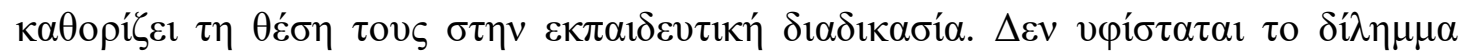

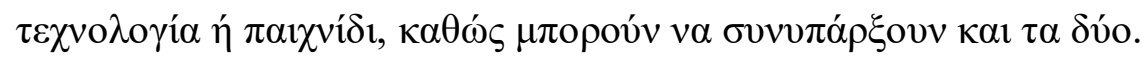

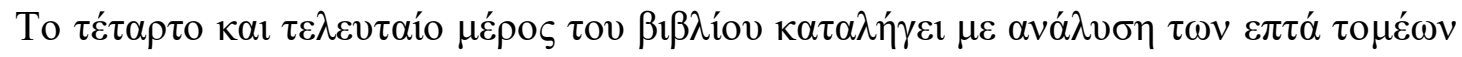

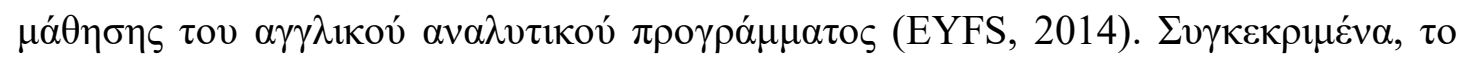

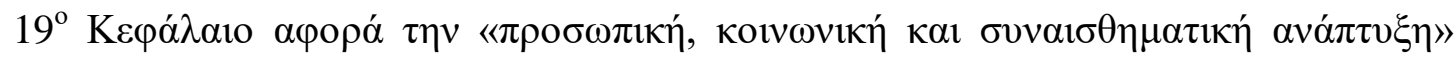

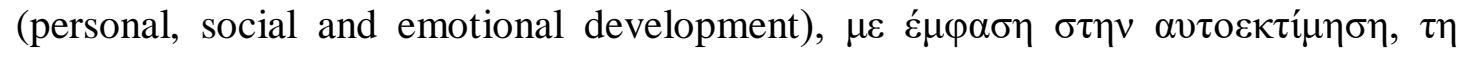

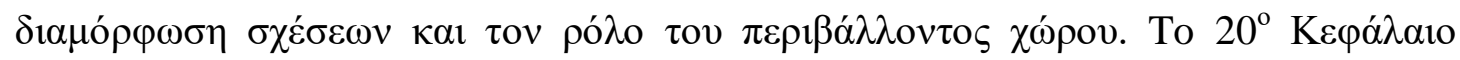

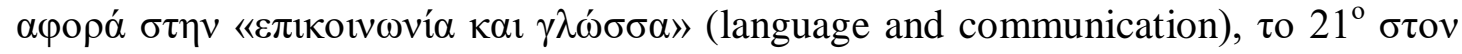

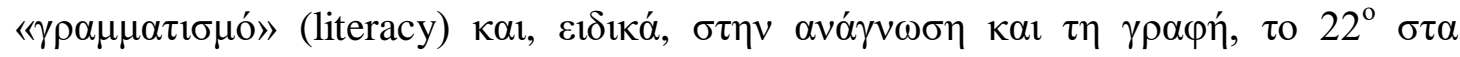

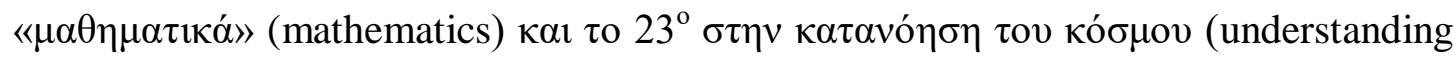

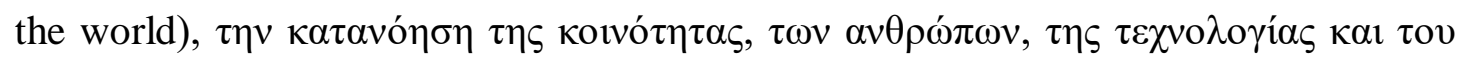

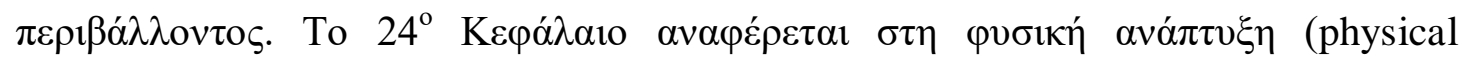

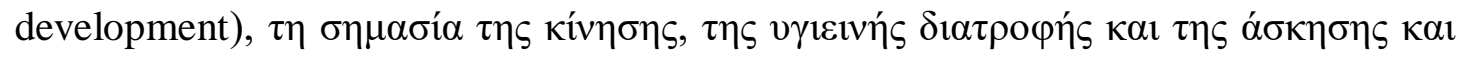

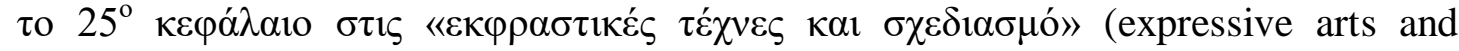

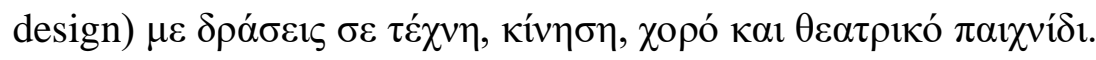

